Vulnerabilidades urbanas en los países andinos (Bolivia, Ecuador, Perú)

\title{
Construcción y refuerzo de la vulnerabilidad en dos espacios marginales de Lima
}

Construction et renforcement de la vulnérabilité dans deux espaces marginaux de Lima

Construction and vulnerability intensification in two marginal spaces of Lima

Jérémy Robert y Alexis Sierra

\section{(2) OpenEdition}

Journals

Edición electrónica

URL: http://journals.openedition.org/bifea/2371

DOI: $10.4000 /$ bifea.2371

ISSN: 2076-5827

Editor

Institut Français d'Études Andines

Edición impresa

Fecha de publicación: 1 diciembre 2009

Paginación: 595-621

ISSN: 0303-7495

Referencia electrónica

Jérémy Robert y Alexis Sierra, « Construcción y refuerzo de la vulnerabilidad en dos espacios marginales de Lima », Bulletin de l'Institut français d'études andines [En línea], 38 (3) | 2009, Publicado el 01 junio 2010, consultado el 10 diciembre 2020. URL : http://journals.openedition.org/bifea/2371 ; DOI : https://doi.org/10.4000/bifea.2371

\section{(9) $\Theta \Theta \Theta$}

Les contenus du Bulletin de l'Institut français d'études andines sont mis à disposition selon les termes de la licence Creative Commons Attribution - Pas d'Utilisation Commerciale - Pas de Modification 4.0 International. 


\title{
Parte 2
}

LOS PROCESOS PASADOS Y ACTUALES DE CONSTRUCCIÓN Y CONSOLIDACIÓN DE LA

\author{
VULNERABILIDAD
}

LeS PROCESSUS, PASSÉS ET ACTUELS, DE CONSTRUCTION ET DE RENFORCEMENT DE LA VULNÉRABILITÉ

THE PAST AND PRESENT CONSTRUCTION PROCESSES AND VULNERABILITY - STRENGTHENING

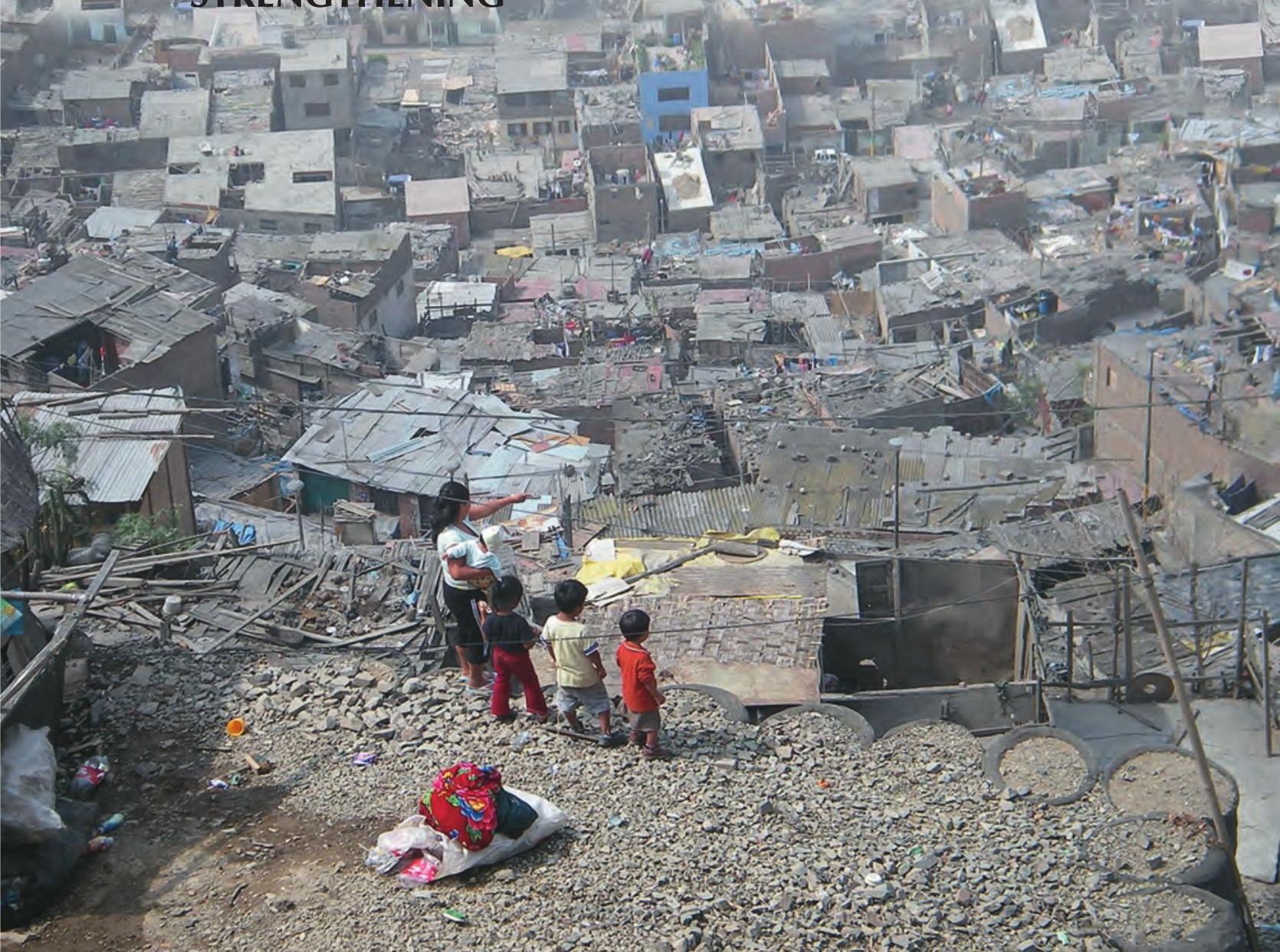





\title{
Construcción y refuerzo de la vulnerabilidad en dos espacios marginales de Lima
}

\author{
Jérémy Robert* \\ Alexis Sierra**
}

\section{Resumen}

Los Asentamientos Humanos ${ }^{1}$ de la Margen Izquierda del Río Rímac (MIRR), y los del Cerro El Agustino, simbolizan los primeros barrios populares e informales de Lima. Estos presentan las características de espacios de riesgo: la precariedad de las condiciones de vida, diferentes formas de marginalidad así como una fuerte exposición a los fenómenos de origen natural y antrópico. Estos espacios son el objeto de una representación del riesgo marcada, tanto desde el punto de vista de la población como del de las autoridades responsables de la gestión del riesgo. Esta representación es variable en función de los retos y de los intereses de cada cual. El análisis de las implicancias de estas representaciones, particularmente a través de las acciones de lucha contra el riesgo, permite aportar elementos para la comprensión de los procesos de construcción y de refuerzo de la vulnerabilidad. En efecto, los factores institucionales y los modos de gobernanza de estos espacios urbanos aparecen como factores claves de la construcción de la vulnerabilidad.

Palabras clave: espacios de riesgo, vulnerabilidad, representaciones, políticas de gestión del riesgo

* Institut Français d'Études Andines (IFEA, UMIFRE 17, CNRS-MAEE), Casilla 18-1217, Lima 18, Perú; Laboratorio EDYTEM, CISM- CNRS, Université de Savoie. E-mail: jeremy.robert@univ-savoie.fr

** Université de Cergy-Pontoise-IUFM, Institut de Recherche pour le Développement (IRD), UR 029, programa Pacivur. 32 avenue Varagnat, 93143 Bondy Cedex, France. E-mail: alexisierra2001@ yahoo.fr

1 La denominación Asentamientos Humanos (AA.HH.) es utilizada en el Perú para describir un tipo de urbanización popular, informal, correspondiente a una unidad territorial. 


\title{
Construction et renforcement de la vulnérabilité dans deux espaces marginaux de Lima
}

\section{Résumé}

Les quartiers de la Margen Izquierda du Río Rímac (MIRR), comme ceux du Cerro El Agustino, symbolisent les premiers quartiers populaires et informels de Lima. Ils présentent les caractéristiques d'espaces à risque, notamment la précarité des conditions de vie, différentes formes de marginalité ainsi qu'une forte exposition aux phénomènes d'origine naturelle et anthropique. Ces espaces font l'objet d'une représentation du risque marquée, tant du point de vue de la population comme de celui des autorités responsables de la gestion du risque, et variable en fonction des enjeux et des intérêts de chacun. L'analyse des implications de ces représentations, notamment à travers les actions de lutte contre le risque, permet d'apporter des éléments pour la compréhension des processus de construction et de renforcement de la vulnérabilité. Les facteurs institutionnels et les modes de gouvernement de ces espaces urbains apparaissent en effet comme des facteurs clefs de la construction de la vulnérabilité.

Mots clés : espaces à risque, vulnérabilité, représentations, politiques de gestion du risque

\section{Construction and vulnerability intensification in two marginal spaces of Lima}

\begin{abstract}
The Margen Izquierda of Río Rímac (MIRR) sector, known as Cerro El Agustino, symbolizes the first popular and informal neighborhoods of Lima. The precarious habitat, the various forms of marginality as well as a strong exposure to the natural and/or anthropomorphic hazards, are some characteristics of those spaces at risk. From the point of view of the inhabitants as well for the public authorities, these spaces are stood represent a marked risk, which varies according to the purposes and the interests of each one. The implications analysis of these representations, in particular through the attempted actions against risks, brings out the elements needed to understand the resulting processes of construction and reinforcement in response to vulnerabilitiy. Institutional factors and government forms of these urban spaces appear as keys factors of the construction of vulnerability
\end{abstract}

Key words: spaces at risk, vulnerability, representation, policy of risk management

\section{INTRODUCCIÓN}

Los Asentamientos Humanos de la Margen Izquierda del Río Rímac (MIRR) y los del Cerro El Agustino se ven regularmente afectados por eventos de origen natural y/o antrópico: deslizamientos de terreno, derrumbes de construcciones, incendios. Según la base de datos DesInventar2, se han registrado 30 accidentes entre 1970 y 2006 en la MIRR, provocando la destrucción de unas treinta viviendas y la muerte

2 Base de datos o «inventario histórico de los desastres» puesta a disposición desde 1996 por LA RED (Red de Estudios Sociales en Prevención de Desastres en América Latina). Esta registra los eventos de diferentes tamaños causantes de daños que han afectado a los países de América Latina desde 1970. 
de una decena de personas. En el caso de los Asentamientos Humanos (AA.HH.) que ocupan las laderas del Cerro El Agustino, 4 eventos aparecen en DesInventar, entre los cuales se encuentra el hundimiento de 2003 que destruyó 20 viviendas en el A.H. 9 de Octubre. Sin embargo, numerosos eventos no aparecen registrados como por ejemplo las frecuentes caídas de piedras o los incendios. El número de hogares afectados y la multiplicidad de las huellas de daños son una de las razones por las cuales estos sectores son considerados como espacios vulnerables.

Más allá de esta constatación, el objetivo de este artículo será doble. Se tratará de identificar y analizar los procesos de construcción de la vulnerabilidad, pero también de mostrar de qué manera las dinámicas actuales perpetúan la vulnerabilidad existente, la amplifican o al contrario la reducen. Estos procesos serán asociados a los espacios y territorios portadores de vulnerabilidad. El análisis de la vulnerabilidad también se enriquecerá con una comparación sistemática entre ambos sectores. Para ello, confrontaremos los procesos pasados y actuales utilizando la dialéctica de las escalas, desde el espacio vivido por los habitantes hasta la escala metropolitana.

En una primera parte presentaremos las características actuales de estos dos espacios vulnerables. Será una ocasión para identificar los diferentes factores de vulnerabilidad, así como para ubicarlos dentro de una perspectiva histórica.

La segunda parte plantea la hipótesis que los intereses de los actores y las relaciones de fuerza influyen sobre los procesos de construcción de la vulnerabilidad y sobre su evolución. Después de haber presentado a los diferentes actores y sus representaciones del riesgo, veremos cómo los desafíos de desarrollo influyen en consideración del riesgo y su traducción en términos de políticas públicas. Apuntaremos también cómo las representaciones y sus implicancias determinan las relaciones entre las autoridades y la población sobre la cuestión de los riesgos.

Por último, el análisis de las políticas públicas nos permitirá ilustrar la materialización de los juegos de intereses y conflictos, así como las implicancias en términos de vulnerabilidad. Previamente nos abocaremos al estudio de los instrumentos jurídicos de la gestión del riesgo, antes de distinguir diferentes tipos de intervenciones públicas. Estas intervenciones son a veces susceptibles de favorecer la prosecución de dinámicas generadoras de vulnerabilidad, en la continuidad de las lógicas antiguas, que pueden traducirse hoy por accidentes.

\section{LA MIRR Y LAS LADERAS DEL CERRO EL AGUSTINO, DOS ESPACIOS VULNERABLES}

Los asentamientos humanos de la MIRR concentran cerca de 80000 habitantes (Censo INEI de 2005), de los cuales aproximadamente 10000 ocupan las riberas del río Rímac, entre la avenida Morales Duárez y el río (fig. 1). Más de 20000 habitantes ocupan los asentamientos estudiados en El Agustino. Los espacios urbanos analizados tienen como característica común ser pericentrales y colindantes con el centro histórico de Lima de manera simétrica: la MIRR se sitúa 


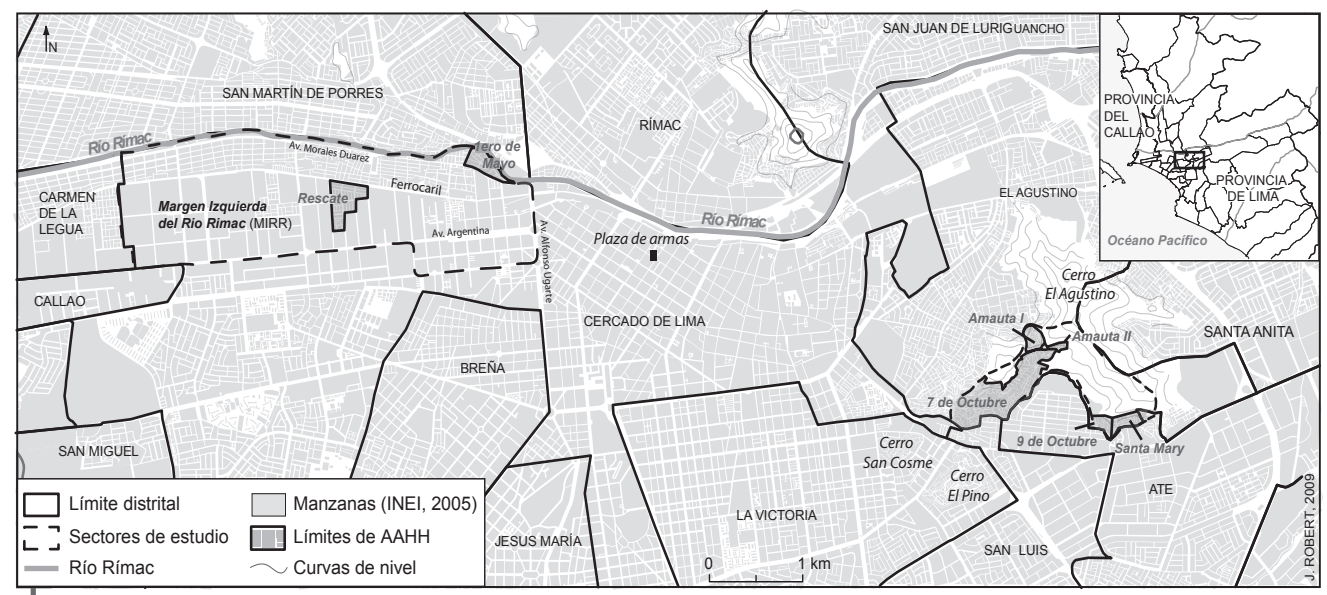

Figura 1 - Localización de los sectores estudiados

al oeste y las laderas del Cerro El Agustino al este. Ambos presentan características de espacios de riesgo y de espacios precarios.

\section{1. Dos espacios urbanos de riesgo}

Tres dimensiones del riesgo definen la condición de espacios de riesgo de estos barrios: la exposición a las amenazas de origen natural y antrópico, una ocupación del territorio generadora de nuevas amenazas y una forma de ocupación que hace difícil la gestión de crisis.

Los barrios de la MIRR están expuestos a diferentes amenazas en relación con las dinámicas hidrográficas y morfológicas del río Rímac. Hasta mediados del siglo XIX, los terrenos estaban expuestos a las inundaciones. Actualmente, las crecidas no afectan ya directamente a los barrios a causa del encajonamiento del lecho menor del río, que puede alcanzar hasta 20 metros de profundidad en ciertos puntos. Sin embargo, el aumento del caudal afecta las riberas por erosión lateral y por procesos de socavación, que favorecen la inestabilidad de estas últimas.

Además, el proceso de ocupación induce nuevas amenazas. En efecto, los barrios han sido edificados en parte sobre rellenos de escombros y de residuos que corresponden a antiguos botaderos. La heterogeneidad resultante de los suelos favorece la inestabilidad y el debilitamiento de las construcciones, lo que enseñan fisuras evidentes en numerosas casas. Estos terrenos tienden también a amplificar las ondas sísmicas (COOPI, 2008; Bernal \& Tavera, 2008). El carácter rudimentario de las construcciones, entre las cuales un gran número han sido autoconstruidas, se añade a la mala calidad de los suelos. El conjunto de estos factores contribuye a acrecentar la vulnerabilidad frente a la amenaza sísmica, ya importante en la región. 
Las riberas del río Rímac constituyen los sectores más críticos (fig. 2): la heterogeneidad de las formaciones superficiales y el socavado de las riberas se conjugan, haciendo que estos terrenos sean muy inestables. La presencia humana acentúa además los procesos físicos. La red informal de evacuación de las aguas usadas, construida por la población que ocupa las riberas, contribuye a su erosión. Las fugas asociadas a las conexiones ilegales a la red de agua potable aumentan también la inestabilidad de los suelos y el daño a las construcciones.

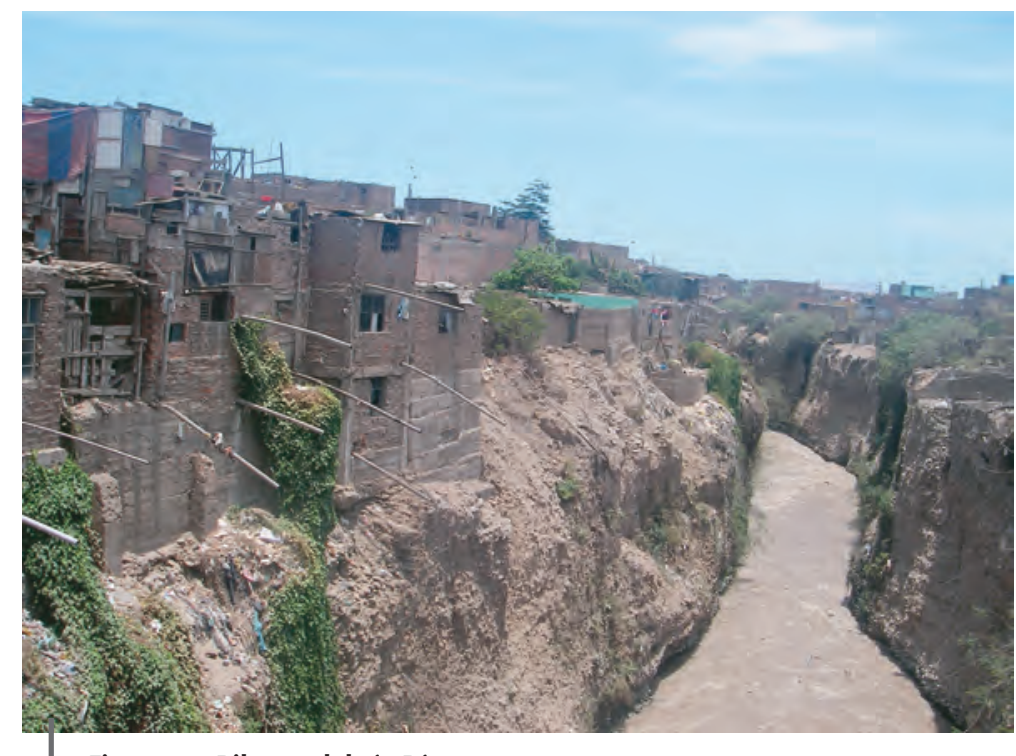

Figura 2 - Riberas del río Rímac

Foto: J. Robert, 2009

Sobre las laderas del Cerro El Agustino (fig. 3), la gran mayoría de las construcciones ocupan fuertes pendientes y están expuestas a los movimientos gravitarios, como caídas de bloques o derrumbes. Además, algunas zonas han sido construidas sobre antiguas galerías o canteras posteriormente rellenadas. La falta de conocimiento preciso y de difusión de los mapas existentes que indican la localización de estos sectores es indudablemente un factor de vulnerabilidad. Además, con el fin de poder ocupar terrenos tan inclinados, las construcciones se realizan sobre micro rellenos, denominados pircas, sostenidos por muros con piedras sin argamasa o sacos de arena. El suelo urbano, autoproducido de esta manera, se caracteriza pues por su inestabilidad, en particular frente a los sismos.

Finalmente, esta extensión urbana se ha realizado de manera muy densa, dejando pocos espacios para las obras de infraestructura vial cuya pendiente y sinuosidad hacen difícil el acceso a las partes altas. Una parte de la población solo puede llegar hasta su vivienda a través de escaleras, más o menos mantenidas. Esto constituye un factor de vulnerabilidad adicional en caso de crisis pues dificulta la evacuación y la intervención de los auxilios. 


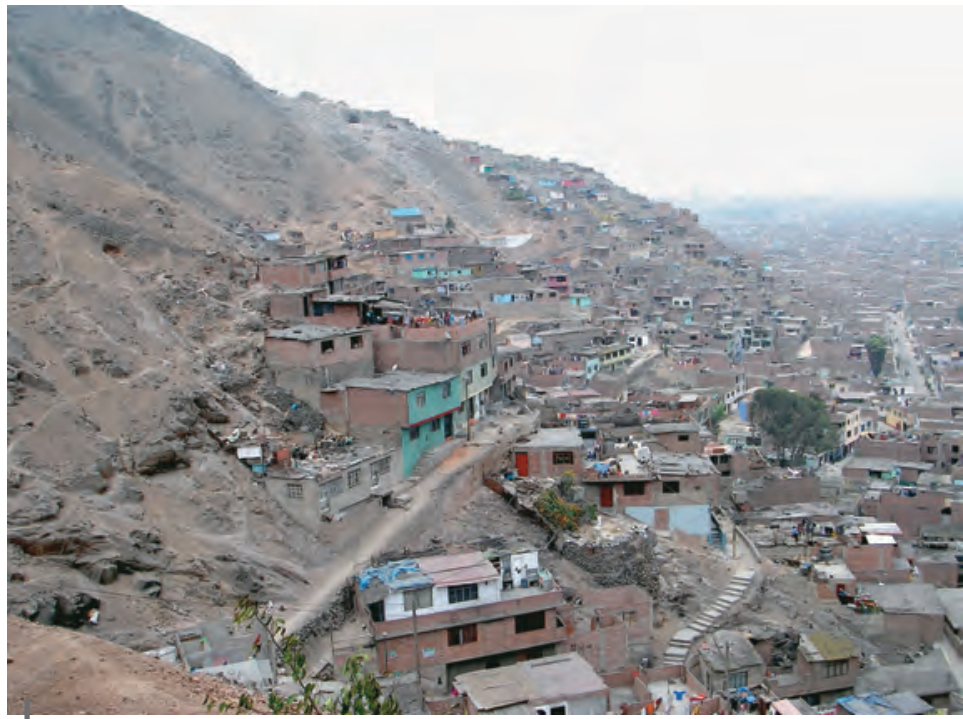

Figura 3 - Laderas del Cerro El Agustino

Foto: J. Robert, 2007

\section{2. Dos espacios urbanos precarios y marginales}

En ambos sectores, los criterios socioeconómicos muestran la existencia de varios factores de vulnerabilidad. Por ser zonas peligrosas, subequipadas y de mala fama, los terrenos son de escaso valor y atraen a una población que necesita alojarse al menor costo. Por ejemplo, según los estudios realizados (Coopi, 2008), 10 \% de la población de la MIRR posee un nivel de educación inferior o igual al ciclo primario (hasta los 11 años), con excepciones puntuales en las que se llega al $15 \%$. En El Agustino, la mayoría de los barrios estudiados registran $15 \%$ de la población con un escaso nivel de educación (primaria), y más del 20 \% en algunos casos. En la MIRR, aproximadamente 10 \% de la población no tiene acceso a la red pública de agua y desagüe, mientras más de un cuarto de la población de los AA.HH. 7 de Octubre y Amauta I y II carece de él.

Existen además grandes diferencias internas en ambos sectores. En la MIRR, más de la mitad de las viviendas situadas sobre las riberas del río Rímac no tienen acceso a la red pública de saneamiento. En El Agustino, las partes altas de las laderas son las que tienen mayores carencias: menos de un tercio de las viviendas están conectadas a las redes públicas de aducción y evacuación de las aguas. Estos indicadores muestran el subequipamiento general, que puede alcanzar en algunos casos niveles críticos. La alta afluencia a los comedores populares3, numerosos en estos sectores, confirma la presencia de una población muy pobre.

3 Estos comedores populares subsidiados por el Estado ofrecen platos de comida a precios módicos para la población más necesitada. 
Las actividades económicas caracterizan también las condiciones de precariedad. En los dos sectores, la mayoría de la población encuestada vive del comercio informal o trabaja como obrero o empleado obteniendo escasos ingresos. Esta se encuentra cerca de fuentes de empleo dinámicas, ligadas a los grandes mercados y a las zonas industriales que concentran todavía grandes fábricas a pesar de la crisis del sector en los años 1980.

Una parte importante de la población de la MIRR vive tradicional e informalmente del reciclaje de basura. Esta actividad es poco conocida y da a la MIRR una imagen de espacio marginal. Esta genera nuevas amenazas, tales como los incendios en depósitos de material inflamable dentro de las viviendas.

La vulnerabilidad de estos espacios urbanos se ve acentuada por el escaso interés de las autoridades, y el sentimiento de abandono de la población. Esta marginalidad determina la percepción que tienen los demás limeños acerca de estos barrios, la cual está estrechamente asociada a una historia de invasiones, de tráfico de tierras y de actividades ilegales (D’Ercole \& Sierra, 2008; Sierra, 2009).

\section{3. El proceso de ocupación}

El análisis histórico de la ocupación y del crecimiento de estos espacios urbanos presenta dos intereses: comprender por qué una parte de la población urbana se expone a las amenazas e identificar las formas de organización generadoras de vulnerabilidad.

Entre los primeros barrios populares ilegales de Lima, conocidos como barriadas, se encuentran los AA.HH. de la MIRR y de El Agustino (Matos Mar, 1977; Driant, 1991). En ambos casos, la ocupación de los terrenos comienza a partir de los años 1940. La expansión urbana aprovecha la proximidad del centro histórico de Lima, atrayendo a migrantes rurales en su mayoría. El proceso es acumulativo: los primeros en llegar constituyen la base de una red social que atrae a nuevos migrantes. Más allá de estas similitudes, el desarrollo urbano es sensiblemente distinto.

En el caso de la MIRR, la ocupación se desarrolla sobre un eje de actividades industriales y de tránsito de interés metropolitano (y regional), entre el centro de Lima y el puerto del Callao. El sector situado al oeste de la avenida Alfonso Ugarte, estaba destinado al desarrollo urbano de Lima y, en particular, para desarrollar actividades que no podían asentarse en el centro histórico (industrias, relleno sanitario, camales, etc.). La producción de suelo urbano y la creación de nuevos barrios se desarrollaron progresivamente desde inicios de los años 1940 entre el centro histórico, el río Rímac y la vía férrea, ocupando tierras agrícolas. Numerosos terrenos han sido rellenados, con el fin de permitir la valorización de zonas pantanosas y del lecho mayor del río, iniciando el proceso de canalización. El espacio ha sido progresivamente ocupado, empujando a la población hacia terrenos dentro de la zona industrial a partir de los años 1970, a veces de manera conflictiva, a semejanza de la ocupación de una antigua fábrica de ladrillos en 
1972 en donde se encuentra hoy el A.H. Rescate. De esta manera, la MIRR se presenta como un desborde del centro histórico de Lima.

El proceso de ocupación es relativamente similar en El Agustino, pero en este último caso, está caracterizado por un evento fundador, seguido de una historia épica y violenta. En 1946, la ocupación del Cerro San Cosme4, cercano al cerro El Agustino, fue considerada como el primer caso de invasión de la propiedad privada por un movimiento masivo y organizado, fenómeno que simboliza desde esa época la barriada limeña (Matos Mar, 1977). El Cerro El Agustino fue invadido poco tiempo después, seguido por un proceso de ocupación progresivo y masivo de las laderas hasta los años 1980. Inicialmente, estas invasiones fueron perpetradas en gran parte por yanaconas (trabajadores agrícolas empleados en las haciendas), y amplificadas luego por los migrantes de otras provincias peruanas. Los nuevos barrios se asentaron sobre los terrenos de la antigua hacienda El Agustino y dieron lugar a violentos enfrentamientos con las autoridades y las fuerzas del orden. Esta forma de desarrollo, caracterizada por una poderosa organización comunitaria, desembocó en la integración de estos barrios que ocupaban las laderas, cuando se convirtieron en distrito en 1965. Lo que consagró el reconocimiento de estos asentamientos y magnificó una historia relatada hoy con cierto orgullo5. En ambos casos, a pesar de la antigüedad de la ocupación y de la posición pericentral, la ilegalidad sigue siendo una constante.

\section{4. Una urbanización marcada por los accidentes}

El proceso de urbanización de estos espacios de riesgo ha estado marcado por accidentes. Durante la estación pluvial, la caída recurrente de casas situadas sobre las riberas del río Rímac suele movilizar a la prensa. Según El Comercio6, desde 1990 se han publicado en Lima 76 notas de prensa dedicadas al riesgo sobre las riberas de río Rímac. Algunos accidentes han sido de gran amplitud, como por ejemplo la destrucción de 13 viviendas en 1975, que obligó las familias a ocupar la avenida Morales Duárez (La Prensa, 1975). Más frecuentemente, las construcciones se inclinaron y colapsaron por trozos, ilustrando un proceso de daños según temporalidades complejas. Es el caso por ejemplo de la caída de una casa que provocó la muerte de una niña en 2005. De nuevo, en 2007, una casa del barrio $1^{\circ}$ de Mayo colapsó parcialmente. En 2008, se produjo el mismo tipo de evento a algunos metros de distancia, provocando esta vez la muerte de una persona.

En la última década, dos eventos principales marcaron los barrios del Cerro El Agustino: en 2002, el hundimiento de un colegio de reciente construcción (1995) y el hundimiento de una zona de relleno del A.H. 9 de Octubre en 2003. Además de estos eventos ampliamente mediatizados, una serie de accidentes de escasa

4 El Cerro San Cosme se encuentra en el distrito de La Victoria, frente al Cerro El Agustino.

5 Testimonio de ello son el himno del distrito así como la historia del distrito publicada por la municipalidad en forma de fascículos.

6 Principal diario del Perú. Datos publicados en la edición de El Comercio del 05/04/2008. 
magnitud han marcado a estos barrios, tal como caídas de bloques, pequeños deslizamientos o fisuración de las construcciones. Según la base de datos del SINPAD7, entre 2003 y 2008 se han registrado siete eventos que afectaron casas y necesitaron ayuda de Defensa Civil8. Por último, los incendios representan también una seria amenaza en estas zonas donde la concentración de las construcciones facilita su propagación. Según los informes del cuerpo de bomberos de Lima, se han registrado más de 150 incendios entre 2003 y 2007 en la MIRR. También se temen los incendios en El Agustino, donde el Sinpad ha reportado 9 incendios desde 2003; el último causó la muerte de dos niños en 2008. Estos accidentes contribuyen a la emergencia de una representación marcada del riesgo.

\section{LAS REPRESENTACIONES DEL RIESGO Y SUS IMPLICANCIAS}

\section{1. Representaciones y actores}

\section{1. 1. La representación del riesgo en la población}

Los riesgos de origen natural y/o antrópico están entre las preocupaciones actuales de las autoridades municipales locales y metropolitanas, de las ONG y de las instituciones internacionales. Por cierto, en los espacios marginales como la MIRR y las laderas del Cerro El Agustino, la población los relativiza frente a otros riesgos sociales ligados a la pobreza, a la falta de trabajo o a la delincuencia. No por ello la problemática del riesgo deja de ser bastante conocida. Los accidentes son regularmente tratados por la prensa, que destaca al mismo tiempo las condiciones de precariedad de estos barrios.

Las diferentes entrevistas efectuadas en estos asentamientos han mostrado que la población era consciente de los riesgos e, incluso, distinguía sus principales causas: la inestabilidad del suelo, asociada a los antiguos rellenos y los diferentes tipos de erosión en la MIRR, la presencia de antiguas canteras en El Agustino, o también la ausencia de criterios técnicos de construcción. Algunos eventos han marcado particularmente su memoria, como el incendio de una casa en la MIRR que causó la muerte de una niña en 2006. Las personas encuestadas insistieron acerca de las condiciones de precariedad en las que viven y en la ausencia de medios para enfrentar las diferentes amenazas a las que se encuentran expuestas.

7 Sinpad: Sistema Nacional de Información para la Prevención y Atención de Desastres. Es una base de datos de los eventos que han ocasionado la distribución de ayuda por parte de Defensa Civil (2003-2009).

8 Defensa Civil: gerencia municipal encargada de la seguridad civil. Todo municipio dispone de una gerencia de Defensa Civil. 


\section{1. 2. Diferentes representaciones del riesgo según actores públicos}

La organización político administrativa, diferente entre los dos sectores, condiciona las representaciones del riesgo.

La MIRR pertenece al distrito del Cercado de Lima, el cual constituye una excepción dentro de la provincia de Lima al no ser considerado en rigor como un distrito. En efecto, el Cercado de Lima es administrado directamente por la Municipalidad Metropolitana de Lima (MML), que actúa sobre el conjunto de la provincia de Lima9. La MML dispone de una doble competencia: la primera a escala de la provincia de Lima y la segunda a escala del distrito, en este caso el Cercado de Lima. Los demás distritos tienen su propia municipalidad y gozan de un alcalde propio a imagen de El Agustino. Por ende, el alcalde del Cercado es el alcalde de la provincia de Lima. La representación colectiva lo plantea primero como alcalde de la provincia y después como alcalde del distrito: en efecto, es elegido por el conjunto de los habitantes de la provincia y no solamente por los del Cercado de Lima.

Sus obligaciones para con toda la metrópoli prevalecen a menudo sobre las del distrito. Ocurre lo mismo con las capacidades de gestión. El distrito del Cercado concentra los medios (personal administrativo, competencias, medios financieros, etc.) pero no los aprovecha con prioridad, puesto que estos son solicitados a escala provincial. Dentro de este contexto, un espacio marginal como la MIRR, en el Cercado de Lima, lo es más aún dentro de la provincia de Lima. Se ve relegado a un segundo plano en las políticas públicas. Esta marginalidad refuerza el sentimiento de abandono vivido por las comunidades.

Los barrios del Cerro El Agustino son también objeto de una cierta marginalización. Forman parte de los barrios más pobres del distrito, poco accesibles y considerados a menudo como focos de delincuencia. Sin embargo, se ven beneficiados con la atención de la municipalidad cuyas competencias se restringen a la jurisdicción administrativa del distrito. La proximidad de los representantes elegidos con la población es más grande, con encuentros regulares, por lo que podemos plantear la hipótesis de que las preocupaciones de la población son aquí más reconocidas.

Las diferencias de contextos político administrativos aparecen como un elemento clave en nuestro análisis de las políticas urbanas, y de las relaciones entre la población y las autoridades municipales. Planteamos entonces que la marginalización y la naturaleza de los vínculos funcionales entre estos sectores y el centro histórico, influyen en las representaciones del riesgo.

9 La provincia de Lima solo representa a una parte del área urbana y alberga a 7605742 habitantes, contra 876877 en la provincia de El Callao. 


\section{2. Representación del riesgo y planificación urbana}

Los documentos de planificación revelan representaciones espaciales distintas del riesgo de parte de las autoridades. Ambas municipalidades disponen de ellos (fig. 4). Su análisis muestra dos maneras muy distintas de aprehender y de representar el riesgo.

\section{2. 1. Reconocimiento del riesgo incompatible con la urbanización en la MIRR}

La cronología contemporánea de la reglamentación urbana muestra el perpetuo afán de frenar la urbanización en la MIRR. En 1996, una resolución administrativa del ministerio de Agricultura creó una «faja marginal» de $20 \mathrm{~m}$ de ancho a lo largo de las riberas del río Rímac, convirtiendo esta zona en intangible10. Esta prohibe toda construcción u ocupación en las riberas por razones de protección ambiental del río y de prevención de los riesgos, en particular de inundación y de erosión11.

Una década después, en 2005, a través de la ordenanza municipal 893, se estableció una «Zona de Reglamentación Especial» (ZRE), que incluyía la «faja marginal» y el barrio $1^{\circ}$ de Mayo. Dentro de esta categoría, se le otorgó el carácter de zona de riesgo mediante la apelación de «Renovación y seguridad urbana»12. Esta clasificación traduce el reconocimiento del riesgo, pero también una indeterminación en cuanto al uso del suelo atribuido a la zona. Esta ordenanza ha sido modificada en 2007 con otra de n. ${ }^{\circ} 1020$ que precisó que la ZRE en cuestión era un sector de alto riesgo, y proscribió la presencia de cualquier tipo de vivienda en ella13.

La sucesión de reglamentos traduce el ideal de un cambio en la ocupación del suelo por parte de las autoridades municipales. Se toma en cuenta el riesgo, pero el reglamento no se aplica de hecho. Defensa Civil notifica todos los años a los ocupantes de las riberas la obligación de «liberar la zona de manera inmediata», sin por ello proponer alternativas.

10 Según la Resolución Administrativa n. ํ 037-96 AG-UADA.LC/ATDR.CHRL (1996), artículo primero, conforme al D.S. 012-94-AG, se delimita la faja marginal del río Rímac en el tramo entre el Puente Santa Rosa y el Puente Dueñas en un ancho de 20 m en ambas márgenes del cauce determinados en forma horizontal a partir de la ribera y medidos en forma transversal al eje del cauce; y de $50 \mathrm{~m}$ por el tramo comprendido entre el Puente Dueñas hasta la desembocadura en el mar.

11 Según la misma Resolución, mediante el oficio 15389, de diciembre de 1995, la jefatura del Indeci considera la faja marginal como una «zona altamente vulnerable a inundaciones [...] a quedar libre para evitar desastres naturales».

12 En efecto, existen otros casos en los que la clasificación ZRE no se justifica por la presencia de riesgo.

13 Art. $6^{\circ}$.- Ordenanza 1020-MML (15-05-07) que modifica la Ordenanza 893 (2005) estipula que: «el área comprendida entre la Av. Morales Duárez, el Río Rímac, la Av. Alfonso Ugarte y el límite con la provincia del Callao, calificada en el Plano de Zonificación del Cercado de Lima como zona de Reglamentación Especial será materia de intervención por parte de las autoridades competentes por tratarse de un sector urbano de alto riesgo, donde no debe permitirse la permanencia de viviendas por representar un peligro para la integridad física de los pobladores». 


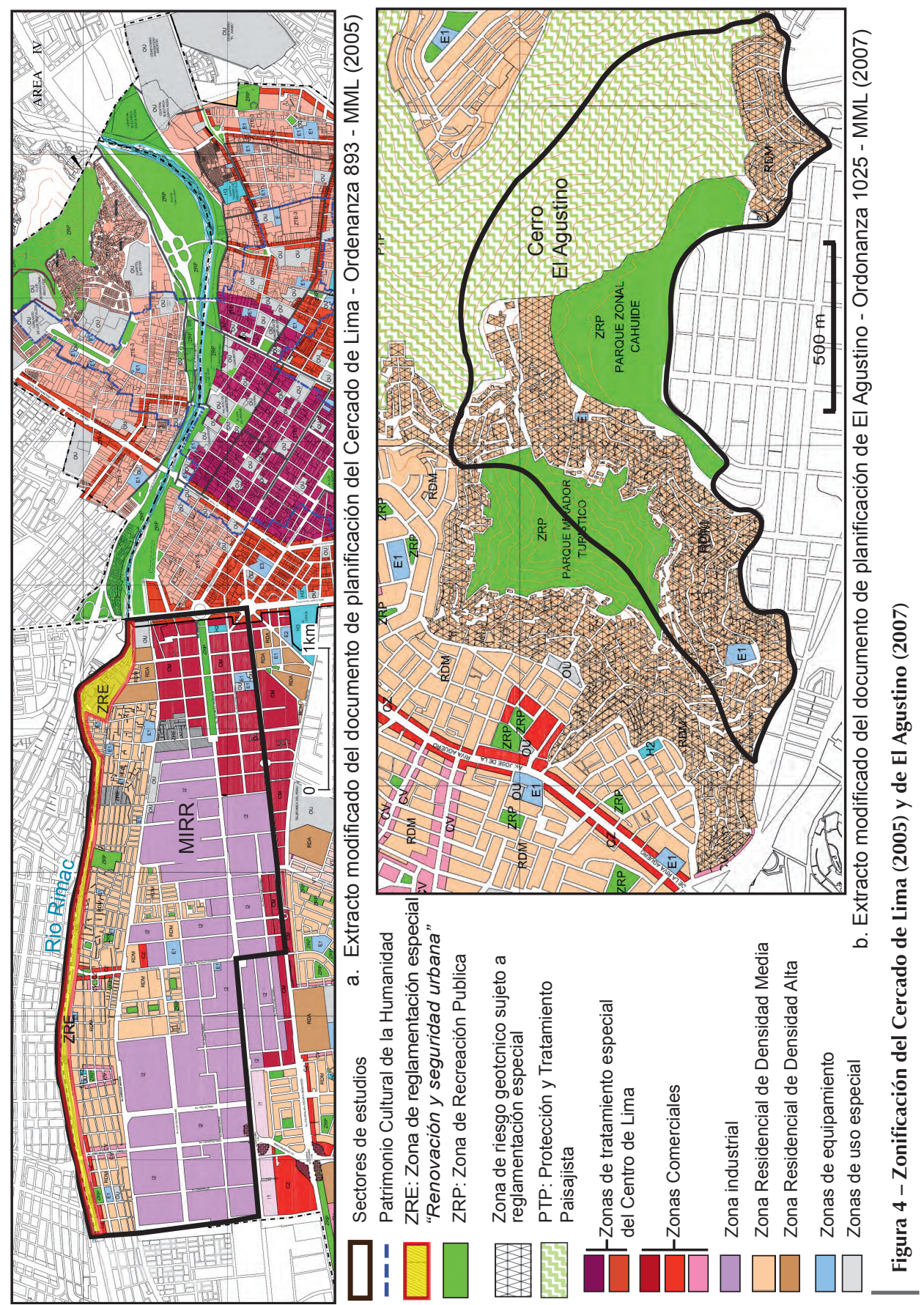




\section{2. 2. Reconocimiento del riesgo compatible con la urbanización en El Agustino}

En el caso de El Agustino, el documento de planificación es realizado en coordinación entre las autoridades municipales competentes y el IMP (Instituto Metropolitano de Planificación), entidad de la MML. Las modificaciones de la ocupación del suelo, propuestas por las autoridades del distrito, son sometidas al IMP, que controla su coherencia a escala metropolitana.

Según la zonificación de 2007 (ordenanza 1025-MML), las laderas del Cerro El Agustino están calificadas como «zona de riesgo geotécnico sujeto a normativa especial». A pesar de este reconocimiento del riesgo, también aparecen como zonas «de uso residencial de densidad media», lo que muestra una forma de aceptación de la urbanización. Sin embargo, según el artículo 9 de la misma ordenanza:

«la ocupación y edificación de terrenos localizados en las laderas del Cerro El Agustino [...] deberá contar necesariamente con la aprobación y la regulación del Instituto Nacional de Defensa Civil (Indeci)».

El reconocimiento del riesgo impone entonces ciertas restricciones, sin que por ello sea incompatible la ocupación residencial.

La clasificación de las partes altas del cerro como «Zonas de Recreación Pública» (ZRP) busca evitar la ocupación de estos terrenos. Esta constituye una medida de reducción del riesgo y muestra los esfuerzos de planificación preventiva. Esto aparece aun más explícitamente con las «zonas de protección y tratamiento paisajista», en los cuales el rol de protección contra las amenazas concuerda con un afán de valorización paisajista14.

Se acepta la urbanización a pesar del reconocimiento del riesgo. Sin embargo, las autoridades muestran su voluntad de control y de limitación de la ocupación de las laderas a través de una política de planificación preventiva explícita. Esta política se acompaña de inspecciones por parte de las fuerzas policiales a fin de evitar nuevas ocupaciones. La planificación preventiva puede representar una solución para evitar el incremento del nivel de riesgo. En ciertos casos, esta constituye también una obligación para las autoridades: al aceptar el riesgo, se comprometen a asumir la responsabilidad del deber de protección hacia la población.

\section{3. Los desafíos detrás de la planificación}

Las diferencias entre las representaciones del riesgo, ilustradas a través de las zonificaciones, son el resultado de opciones políticas muy influenciadas por los desafíos del desarrollo.

\footnotetext{
14 Art. $8^{\circ}$.- Zona de Protección y Tratamiento Paisajista, Ordenanza 1025 (MML, 2007).Tiene como objetivo: «Prohibir la ocupación de áreas calificadas como Zona de Protección y Tratamiento Paisajista (PTP) así como la de las áreas declaradas como zona de riesgo por Indeci, a fin de evitar posibles riesgos físicos de los Asentamientos Humanos. En estas áreas deberá promoverse proyectos de arborización, recubrimiento vegetal, tratamiento paisajista y de protección y seguridad física».
} 


\section{3. 1. Desafíos de desarrollo metropolitano en la MIRR}

En la MIRR, al considerar la urbanización incompatible con el riesgo, las autoridades entran en conflicto con la población. Queda claro que las riberas del río Rímac no deberían estar ocupadas por viviendas, y que los barrios representan incluso un obstáculo para el desarrollo de proyectos urbanísticos de interés metropolitano.

La valorización de las riberas del río Rímac es un proyecto ya antiguo. A finales del siglo XIX, el Plan Regulador del arquitecto Sada propuso el desarrollo del eje LimaCallao donde se origina la actual avenida Argentina, así como la creación de un parque urbano sobre las riberas del río Rímac, diseñado por el ingeniero Meiggs en 1876. Este parque habría sido el más grande de Lima.

El desarrollo del eje que conduce al puerto del Callao sigue teniendo un interés de actualidad, como lo demuestran los proyectos urbanísticos de recuperación de las riberas, desde el centro histórico hasta la desembocadura del río. El programa de renovación urbana de la margen izquierda del río Rímac y el plan de ordenamiento de la avenida Argentina son considerados como el proyecto «más importante del país y de Lima Metropolitana» (Ministerio de Vivienda, MML, Revista Waka). Este plan propone la «recuperación del río Rímac y de estas márgenes» y «destinar las áreas recuperadas para áreas verdes sin uso recreativo por falta de estabilidad de la zona». Esta es una referencia del reconocimiento del riesgo. Además, este proyecto «se debe inscribir dentro de un rol metropolitano y regional y no puede supeditarse al asentamiento precario de poblaciones marginales pues el interés metropolitano debe estar por delante». La clasificación como «Zona de Reglamentación Especial» (ZRE) fortalece los proyectos de desarrollo urbano, justificados por el interés metropolitano.

Sobre la zonificación (fig. 4a), las riberas del río Rímac están clasificadas como «Zonas de Recreación Pública» (ZRP) río arriba de la MIRR y representan el primer paso de la construcción de un parque metropolitano. La valorización de las márgenes a la altura del centro histórico ha sido favorecida por la clasificación del sector como «Patrimonio Cultural de la Humanidad». Las márgenes de la MIRR son espacios potenciales para la ampliación de este parque.

\section{3. 2. Desafíos de desarrollo local (o voluntad de mejoramiento de las condiciones de vida locales)}

Las laderas del Cerro El Agustino no son propicias para el desarrollo urbano. Pese a que no representan una atracción mayor para las grandes inversiones, la municipalidad busca que estas sean una ventaja, particularmente a través de su puesta en valor paisajistica e identitaria.

Como lo muestra el documento de planificación, la municipalidad trata de conjugar el control de la urbanización con un mejoramiento del medio ambiente urbano (fig. 4b). Este compromiso, opuesto a la marginalización observada en el caso de la MIRR, ilustra la integración del Cerro El Agustino en las políticas municipales. Los asentamientos que ocupan sus laderas son considerados, dentro del distrito, 
como un desafío de desarrollo en sí. Su importancia, en términos cuantitativos y cualitativos juega a su favor. Los AA.HH. 7 de Octubre, 9 de Octubre, Santa Mary, Amauta I y II, albergan aproximadamente a 20000 personas, o sea $10 \%$ de la población total del distrito. Además de ser visibles, también forman parte integrante de la identidad local y de la historia de El Agustino.

\section{4. Las consecuencias de la planificación}

La posición de las autoridades frente al riesgo, ilustrada por la zonificación, pone en relieve representaciones muy diferentes. Estas últimas, y los conflictos de intereses asociados, influyen en los procesos de construcción de la vulnerabilidad.

\section{4. 1. Enfrentamiento en la MIRR: la ausencia de solución frente a las reivindicaciones de la población}

La MIRR aparece como un espacio de enfrentamiento entre la población que ocupa las zonas de riesgo y las autoridades. La zonificación muestra la voluntad de las autoridades por recuperar estos terrenos, lo que implica la expulsión de la población. Esta última aparece entonces como un obstáculo para la realización de proyectos metropolitanos. La zonificación fortalece el punto de vista de Defensa Civil metropolitana que, considerando que el riesgo no puede ser eliminado ni reducido, propone como única salida la reubicación de la población concernida.

Ahora bien, las operaciones de reubicación son aceptadas con dificultad por la población. Esta resistencia se explica por el alejamiento de las zonas de reubicación, y las ventajas que presenta el sector de la MIRR. Por cierto, según una encuesta realizada por la ONG Coopi y la MML en abril de 2008 entre la población que ocupa las márgenes del río Rímac, de 403 personas interrogadas, 286 (o sea el $71 \%$ ), serían favorables a la reubicación. Empero, 252 de estas 286 personas (es decir el 88 \%), no la aceptarían sino con la condición de que la reubicación se hiciera en el sector.

En efecto, la proximidad del centro es una ventaja considerable para esta población. La gran mayoría de los empleos formales (fábricas, comercios, etc.) e informales (vendedores ambulantes, recicladores, etc.) son directamente dependientes de esta cercanía. Habitar en zonas alejadas implicaría costos de transporte prohibitivos para numerosos hogares, así como la pérdida de vínculos sociales, culturales y familiares.

La antigüedad de la ocupación desempeña también un rol importante en cuanto a la apropiación de los terrenos y la reivindicación del derecho a la propiedad. Además, esta favoreció la consolidación de los barrios y la acumulación de bienes, entre los cuales la casa es para muchos el único capital. Este proceso de apropiación del espacio se ha hecho a fuerza de luchas y de reivindicaciones, contra las autoridades municipales y sus políticas urbanas. Según los dirigentes de los asentamientos que ocupan las riberas del Rímac, cierto número de 
habitantes han logrado incluso adquirir su título de propiedad (aproximadamente $10 \%$, según los dirigentes de los barrios), a pesar de estar instalados sobre la faja marginal inconstruible. Estos hechos muestran la ausencia de seguimiento en el tiempo de las políticas públicas y generan aún más contradicciones en cuanto a su aplicación. Este contexto se vuelve entonces propicio para la consolidación de los asentamientos y para la libre iniciativa de la población.

Observamos pues una situación de enfrentamiento entre la población y las autoridades, pues la MIRR presenta ventajas que la población no está dispuesta a perder (entre ellas la proximidad del centro, las redes sociales y la antigüedad de la ocupación), y que van en contra de los proyectos de reubicación propuestos por las autoridades. Estas últimas, con el pretexto del reconocimiento del riesgo, se niegan además a tomar en cuenta las reivindicaciones de la población, bloqueando las iniciativas de mejoramiento del medio ambiente urbano.

\section{4. 2. Búsqueda de un acuerdo común en El Agustino}

En el caso de El Agustino, observamos la voluntad de las autoridades por mejorar las condiciones de ocupación limitando al mismo tiempo el riesgo. En parte es el resultado de un conflicto fuerte y antiguo entre población y autoridades. Estas aplican entonces una estrategia para evitar el enfrentamiento e intentan resolver los problemas ligados a la precariedad y a los diferentes factores de vulnerabilidad. Por eso prefieren integrar estos asentamientos en la legislación en vez de negarlos. Esto se traduce de dos maneras: por un lado, limitan y controlan su urbanización y, por otro lado, aplican una política de reducción del riesgo (obras de protección, sensibilización de la población, etc.). Empero, la gran mayoría de la población no dispone de título de propiedad y el reconocimiento del riesgo representa un freno a su proceso de legalización pues la urbanización también puede ser cuestionada, como ocurre en la MIRR.

Ante esta oportunidad de integración, la población mantiene un doble discurso. Cuando su presencia es cuestionada, tienden a minimizar el riesgo. Es el caso, por ejemplo, del dirigente del A.H. 9 de Octubre quien, tras el sismo de 2007, presentó así su visión del riesgo: «el cerro sigue en pie y nada se ha movido». Sin embargo su barrio sufrió un hundimiento en 2003 que destruyó 20 casas, y los estudios han mostrado la presencia de antiguas galerías subterráneas debidas a la explotación minera debajo de todo el el barrio (Colegio de Ingenieros del Perú, 2003).

Además, el riesgo también puede ser utilizado como medio de reivindicación, con el fin de solicitar obras urbanas. Las condiciones de vulnerabilidad son entonces enfatizadas, justificando la necesidad de mejorar el medio ambiente urbano mediante muros de contención y el mejoramiento de los accesos, en particular a través de la construcción de escaleras.

Las diferentes representaciones del riesgo ilustran la negociación y las tensiones entre las autoridades y la población, sin por lo tanto llegar a una situación de 
enfrentamiento. Estas tienen implicancias directas sobre las políticas públicas de gestión de los riesgos.

\section{LAS POLÍTICAS PÚBLICAS DE TRATAMIENTO DE LOS ESPACIOS VULNERABLES}

Las políticas públicas llevadas a cabo en estos espacios vulnerables muestran la existencia de representaciones a veces contradictorias. La posición de las autoridades frente al riesgo, a través de la reglamentación y la planificación, tiene implicancias en las intervenciones públicas que buscan, más o menos directamente, la reducción de los riesgos. Sin embargo, estos instrumentos y estas intervenciones públicas proceden de una negociación con las reivindicaciones comunitarias independientes de los riesgos y no modifican sino marginalmente las dinámicas generadoras de peligros.

\section{1. Los instrumentos jurídicos de la intervención pública}

La legalización de la propiedad es una de las herramientas a disposición de las autoridades municipales para actuar sobre los espacios de riesgo. Esta hace intervenir diferentes actores locales y nacionales: la Comisión de Formalización de la Propiedad Informal (Cofopri), organismo del Estado, la municipalidad distrital y provincial, y Defensa Civil. El proceso es largo y pasa por complejos circuitos burocráticos. La existencia del riesgo es uno de los criterios de la ausencia de formalización de la propiedad.

Cuando Cofopri sospecha la existencia de un riesgo, solicita un estudio a la Municipalidad de Lima, implicando en ello a Defensa Civil metropolitana y a la gerencia de Desarrollo Urbano. Se presentan entonces dos posibilidades: cuando el nivel de riesgo es considerado «medio», Defensa Civil formula algunos requerimientos para acceder a la legalización, como por ejemplo la construcción de muros de contención a cargo de la comunidad. Cuando el nivel de riesgo es considerado «alto» (es decir que no puede ser eliminado ni reducido), Defensa Civil rechaza la legalización y se contempla una propuesta de reubicación. Este es el caso de los AA.HH. que ocupan las márgenes de la MIRR, en donde solo $10 \%$ de los 10000 habitantes poseen título de propiedad. En los asentamientos del Cerro El Agustino, en el que $80 \%$ de los 20000 habitantes carecen de título de propiedad, el proceso de legalización está en curso.

La legalización de la propiedad es también una condición necesaria para la intervención pública, pues da derecho a los equipamientos urbanos tales como el acceso a las redes de agua y de electricidad (Ramírez Corzo \& Riofrío, 2006; PNUD, 2007). Por este hecho, el rechazo de la legalización es un medio de bloquear el desarrollo del barrio. Constituye un instrumento de la política de lucha contra el riesgo.

La zonificación es utilizada de la misma manera, como argumento de (no) intervención. Así, la municipalidad orienta las acciones de tratamiento de estos 
espacios en conformidad con la planificación adoptada. Salvo excepciones, la zonificación de la MIRR justifica el rechazo de equipar a los asentamientos, aunque esta marginalización no provoca la partida de la población residente. En El Agustino, a pesar de la representación del espacio de riesgo, la ocupación de las laderas parece aceptada por cuestiones de realismo. La zonificación no impide equipar los terrenos ya ocupados. En vez de contemplar la expropiación, la idea es de reducir los factores físicos de vulnerabilidad mediante aterrazamientos y muros de contención.

Sin embargo, las intervenciones municipales pueden entrar en contradicción con la planificación establecida, en particular cuando estas responden a la presión de la población.

\section{2. Las intervenciones públicas de tratamiento de los espacios vulnerables}

Las autoridades municipales deben responder a las necesidades cotidianas de la población y luchar al mismo tiempo contra los riesgos. No obstante, la incidencia de las políticas públicas de tratamiento de los espacios ante la vulnerabilidad es muy variable: buscando o no la lucha contra el riesgo, algunas intervenciones reducen la vulnerabilidad de la población, mientras otras tienden a aumentarla. Las acciones municipales de tratamiento de los espacios vulnerables resultan entonces muy variadas en función de su línea de mira y de su impacto sobre la vulnerabilidad. Estas acciones intervienen a menudo tras una crisis, pero cada vez más resultan de una representación del riesgo en tiempo normal. Utilizamos el término de acciones más que el de políticas porque, si bien algunas acciones son la resultante de un programa organizado, planificado e institucionalizado, la mayoría son al contrario puntuales y responden a preocupaciones coyunturales.

\section{2. 1. Desplazar a la población para reducir su exposición a la amenaza}

De conformidad con la planificación, las municipalidades pueden bloquear todo acceso a la propiedad en las zonas juzgadas inconstruibles y hasta desalojar a la población que se habría instalado allí ilegalmente.

La MIRR ha sido objeto de varios proyectos de reubicación, sin poder llegar a la liberación de las riberas. Un proyecto que incumbe a entre 400 y 600 familias, según la prensa de entonces15, fue impulsado tras una serie de accidentes en el transcurso de los años 1970. El ministerio de Vivienda, en coordinación con la Municipalidad de Lima, Defensa Civil, y el Sistema Nacional de Apoyo a la Movilización Social (Sinamos), identificó terrenos en la periferia de Lima, en Canto Grande (San Juan de Lurigancho) y en Ventanilla. El proyecto fue parcialmente aplicado y gran parte de las personas que aceptaron partir regresaron a ocupar sus

${ }^{15}$ El Comercio, 29/04/1977; El Comercio, 19/04/1978; La Crónica, 19/04/1978. 
viviendas iniciales (las que no habían sido destruidas). Victoriano Prieto, padre de siete hijos, nos da su testimonio:

«Hace tres años, cuando el río se llevó nuestras viviendas, los del Sinamos ofrecieron reubicarnos. Y nos llevaron hacia la zona de Canto Grande [...] en donde no teníamos agua, luz, ni colegios. Por eso tuvimos que regresar, con peligro de nuestras vidas» (Expreso, 1981).

En 1982, tras la erosión de la margen que amenazaba el Coliseo (a la altura de la primera cuadra de la avenida Morales Duárez), el ministro del Interior Gagliardi insistió sobre la necesidad de liberar la margen del río Rímac:

«sabemos que muchas personas se resistirán a ser trasladadas pero tendremos que utilizar fuerza pública para sacarlos y de esta manera salvarles la vida» (El Comercio, 03/02/1982).

Estas operaciones de reubicación no fueron ejecutadas y las márgenes del río continúan siendo ocupadas.

La reubicación es más fácil de realizar tras una crisis que ha destruido viviendas. Después del hundimiento que afectó el A.H. 9 de Octubre en 2003 en El Agustino, la municipalidad tomó a su cargo la reubicación de 20 familias dentro del distrito. Estas deben beneficiarse con una vivienda en un complejo inmobiliario actualmente en obras, La Pólvora, resultado de un programa de construcción de viviendas sociales y de comercios. La zona fuertemente afectada ha sido declarada inconstruible y ha sido transformada en plaza pública. La amplitud del accidente favoreció la concretización de esta operación, la misma que en otro contexto habría sido difícilmente realizable. Sin embargo, la situación permanece en suspenso para el resto del barrio.

\section{2. 2. Ordenar para reducir el impacto de la amenaza}

La municipalidad de El Agustino, teniendo conocimiento de la presencia de la población en las laderas de fuertes pendientes, no ha buscado cuestionar su ocupación, aunque lo ha hecho excepcionalmente en el caso del A.H. 9 de Octubre. Optó por construir obras de protección, en particular muros de contención. Esta opción revela cierta fe tecnicista en el dominio de las procesos físicos. Es el caso por ejemplo del A.H. Santa Mary en el cual los muros en construcción refuerzan las terrazas sobre fuertes pendientes (fig. 3). En general, desde 2004, todos los barrios estudiados han sido puntualmente equipados con muros de contención. Plantar árboles sobre las alturas de las laderas del Cerro El Agustino es otra acción que busca directamente impedir la exposición al riesgo. Este acondicionamiento tiene por objetivo estabilizar las pendientes y limitar la expansión urbana hacia esos sectores. En conformidad con el plan de planificación, este entra en coherencia con las políticas de ordenamiento y de desarrollo del distrito, cuya municipalidad desea mejorar la imagen, particularmente creando espacios de recreo.

Sin embargo, algunas obras de contención provocan efectos perversos. Inicialmente construidos con el fin de proteger las viviendas de abajo, ahora sirven de terrazas que facilitan el acceso a nuevas construcciones hacia arriba. 
Estas obras participan indirectamente en la consolidación de la urbanización de las laderas. Igualmente, la construcción de un local comunal en Amauta I o un campo deportivo en Amauta II llevan a reforzar el carácter urbano y a favorecer el lado ciudadano de estos espacios urbanos.

\section{2. 3. Ordenar para mejorar la accesibilidad}

Encontramos los mismos efectos perversos en el mejoramiento de la accesibilidad de los barrios. La dificultad de acceso es un factor de vulnerabilidad reconocido en caso de crisis porque aumenta el tiempo de llegada de los auxilios y la evacuación de los heridos. Empero, en el caso de El Agustino, cuando la municipalidad mejora la accesibilidad de las partes más altas de las laderas del cerro, está favoreciendo también la intensificación de la urbanización. Está actualmente en construcción una vía asfaltada que lleva directamente del centro del distrito hasta el paso en donde se encuentran los AA.HH. Amauta I y Amauta II. A escala de los barrios, se están acondicionando escaleras y vías peatonales que siguen las curvas de nivel. Por cierto, el mejoramiento de la accesibilidad es una necesidad cotidiana e, incluso si no está pensada en función de la eventualidad de una crisis, reduce de hecho la vulnerabilidad al facilitar la evacuación y la intervención de los auxilios. No obstante, a pesar de las mejoras, estas obras contribuyen a perennizar las instalaciones en las laderas, e incluso a favorecer su expansión. Ocurrió lo mismo cuando la municipalidad de Lima decidió reconstruir el puente peatonal Rayito que cruza el río Rímac (en la MIRR) tras su hundimiento en 2006: se trata de un acondicionamiento urbano que restablece una forma de accesibilidad, pero que acrecienta la puesta en exposición de la población a los movimientos de masa.

En el mismo sector, la construcción del puente Delgado de la Flor muestra otra forma de intervención con incidencias en términos de vulnerabilidad. Esta obra, que busca mejorar la movilidad a escala metropolitana, ha requerido la expropiación de cinco casas instaladas al borde del río Rímac, en una zona de alto riesgo. Indirectamente, esta ha llevado a reducir el número de personas expuestas a los derrumbes. Sin embargo, este proyecto de interés metropolitano no responde directamente a los intereses de la población local. Este proyecto ilustra la prioridad de los desafíos metropolitanos y la voluntad de cambio progresivo del uso de la zona, impulsado por la municipalidad provincial. El desarrollo de grandes ejes viales y de la zona comercial a proximidad a lo largo de la avenida Argentina, es en efecto uno de los objetivos municipales, claramente visible en el documento de planificación.

\section{2. 4. Ordenar para reducir la marginalidad}

Algunas acciones son implementadas con fines a responder a las expectativas de la población. Estas pueden tener implicancias en términos de riesgo: la construcción de un Boulevard en los AA.HH. $1^{\circ}$ de Mayo y 2 de Mayo refuerza por ejemplo la puesta en exposición a las amenazas (fig. 5). 


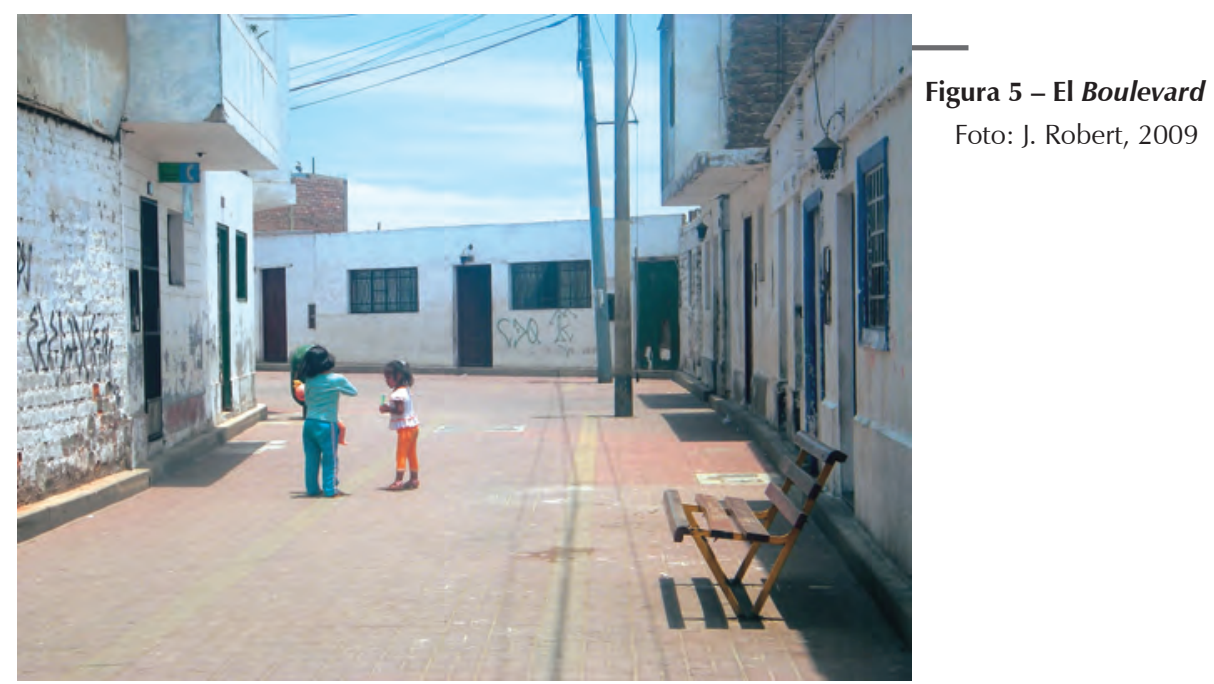

Esta calle peatonal solo está separada del río Rímac por una fila de casas construidas al borde de la ribera e instaladas sobre la faja inconstruible. Con motivo de las elecciones municipales, el alcalde decidió embellecer este sector adoquinando esta calle, colocando rejas en las entradas y rampas en las escaleras, repintando las fachadas, instalando bancos y rehabilitando un local asociativo. Esta nueva apariencia borra toda huella de riesgo y parece contradecir cualquier veleidad de expropiación. Genera un sentimiento de seguridad a pesar de encontrarse en una zona particularmente expuesta. Este tipo de operación tiende incluso a acrecentar el valor de los terrenos al reforzar el atractivo del barrio.

Este caso es igualmente interesante en relación con el tratamiento de una ribera urbana. Las autoridades se encuentran frente a un dilema real: si la municipalidad desarrolla servicios y ordenamientos, refuerza la puesta en exposición de los habitantes; si no hace nada, refuerza la marginalidad de estos asentamientos y el sentimiento de abandono que es su corolario. Sin embargo, es difícil ocultar las necesidades y las reivindicaciones de una población que, sea cual fuere el estatuto legal de los terrenos, está presente hace unos 60 años.

La lógica clientelista, exacerbada en periodos electorales, o cuando ocurren eventos tales como los accidentes relatados por la prensa, se encuentra en gran parte de las intervenciones. En el caso de la MIRR, las obras enarbolan los colores de la municipalidad, como el Boulevard o los diferentes puentes, y todas llevan el nombre del alcalde. Esta política social, basada en la ostentación política, es caracterizada por el programa de construcción de escaleras efectuado por la MML en toda la provincia. En el distrito de El Agustino, habida cuenta del número de habitantes que ocupan las laderas del Cerro El Agustino, es difícilmente imaginable no tomar en cuenta sus reivindicaciones. Los programas de obras de protección entran en parte dentro de esta lógica. 
Por un lado, este modo de gobierno tiende a dejar en manos de la población la responsabilidad del ordenamiento territorial. Esta tiene que mendigar y hacer valer sus reivindicaciones ante las autoridades con el objetivo de obtener una intervención. Por otro lado, también un fenómeno de (auto) organización y de toma de autonomía, asociado al contexto de marginalización y de inmovilismo político. Esta situación contribuye a la prosecución de las dinámicas sociales.

\section{3. La prosecución de las dinámicas sociales}

El proceso de toma de decisión, largo y complicado, tiende a dejar libre curso a las dinámicas sociales en marcha. Estos lastres no son exclusivos de una ciudad como Lima (ni de la América Latina), aun cuando el lenguyelismo jurídico parece más exacerbado aquí que en otros lugares. Sin embargo, en Lima, la diferencia entre el ritmo de crecimiento demográfico y espacial de la ciudad y la duración de la toma de decisiones está particularmente marcada. Esta lentitud representa un problema frente a la urgencia que plantean ciertos factores de vulnerabilidad.

Por este hecho, en ausencia de intervención de las autoridades, el desarrollo de estrategias de reducción de las vulnerabilidades recae en la población, cuyo propósito es mantener su residencia y actividades en una zona peligrosa. Ahora bien, observaremos que esta situación se acompaña a menudo del aumento de las condiciones de vulnerabilidad. Este fenómeno está ligado a la prosecución de las dinámicas sociales, obligadas por las condiciones de pobreza, de precariedad y de ausencia de control.

\section{3. 1. La densificación}

La densificación es una de las dinámicas generadoras de vulnerabilidad. Esta es producto de la confrontación de la presión urbana y del inmovilismo político, exacerbado por la ausencia de control. En efecto, las tierras de nadie son particularmente propicias a la densificación urbana y a la perpetuación del proceso de invasión. Este último comenzó hace más de 60 años y permanece activo, aunque su amplitud es menor. Además, aun si el proceso de migración ha disminuido considerablemente, el crecimiento demográfico de las familias (dado el crecimiento natural) continúa generando une necesidad de espacio. La densificación vertical, mediante la construcción de pisos adicionales, es una primera respuesta (fig. 6). La falta de medios y la ausencia de criterios técnicos, sumada a la inestabilidad del suelo, hace que estas construcciones sean particularmente vulnerables a la amenaza sísmica.

La segunda opción consiste en ocupar los terrenos que quedan libres. En el caso de El Agustino, este fenómeno se ha traducido en la construcción de cerca de 80 nuevas viviendas en los últimos 5 años (según una estimación de los dirigentes), lo que representa aproximadamente 200 personas. Situadas en las partes altas de las laderas, estas no tienen acceso a los servicios más elementales. Las condiciones de accesibilidad son a menudo mediocres, caracterizadas por senderos escarpados 


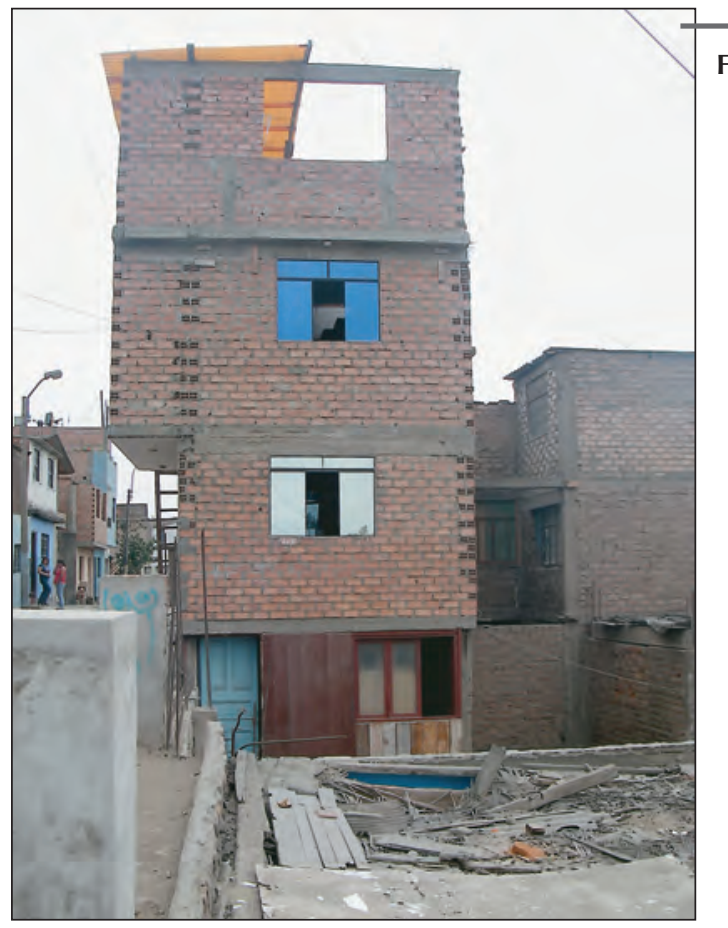

Figura 6 - Densificación vertical en la MIRR

Foto: J. Robert, 2008

o escaleras rudimentarias (fig. 7). Además, la ocupación se realiza mayormente mediante la construcción de pircas, sobre las cuales se edifican después las casas (fig. 8). Estos acondicionamientos contribuyen a la exposición de las laderas a los movimientos gravitarios y a la amenaza sísmica. En la MIRR, la ocupación del pie del antiguo relleno sanitario El Montón en 2006 es otro ejemplo de la presión demográfica. Dieciocho familias decidieron ocupar este sitio particularmente insalubre, pero cercano a su residencia inicial donde pertenece una parte de la familia.

La valorización del bien es también un factor de densificación. La subdivisión de las viviendas, con el objeto de alquilar parte de ellas, es frecuente. Las condiciones de promiscuidad que ello provoca son un factor de vulnerabilidad, dando origen a fuertes concentraciones de población, pero también a problemas sociales y sanitarios. Esta densificación, además de estos efectos directos sobre la vulnerabilidad, tiende a hacer más compleja la gestión del riesgo (y de crisis), al implicar siempre más personas, y situaciones distintas.

\section{3. 2. La población toma a su cargo el acondicionamiento}

La ausencia (o la negativa) de intervención de las autoridades lleva a la población a realizar ella misma los acondicionamientos necesarios para su mantenimiento. Esto no se restringe solamente a las viviendas sino que atañe también a los equipamientos urbanos. 


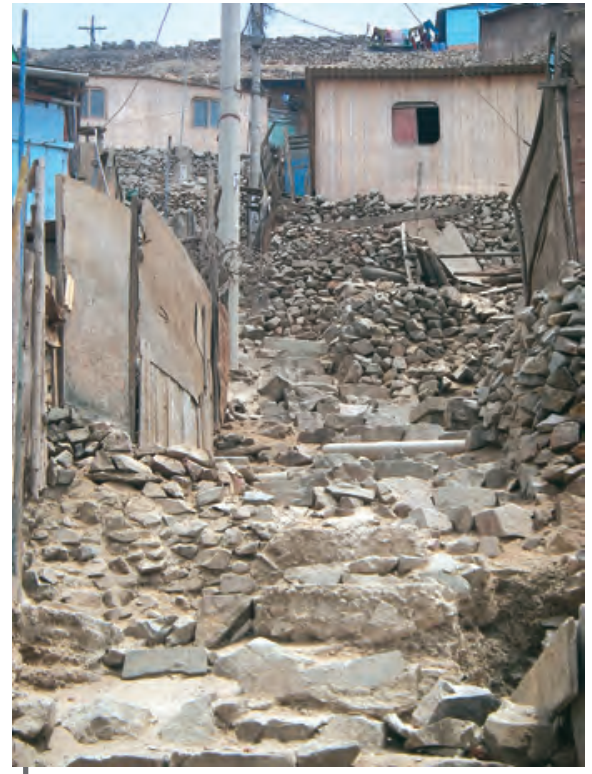

Figura 7 - Escaleras en el A.H. 7 de Octubre

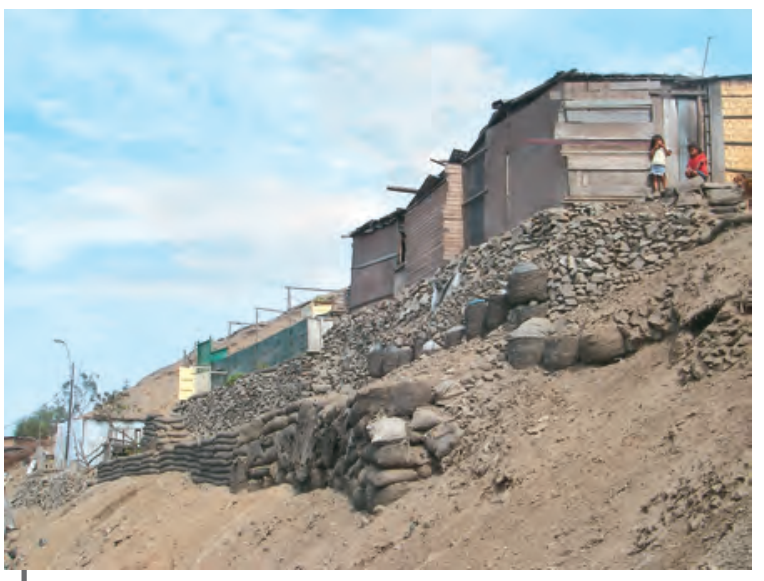

Figura 8 - Ocupación de las partes altas de las laderas en el A.H. 7 de Octubre

Foto: J. Robert, 2009

Foto: J. Robert, 2008

En la MIRR, la decisión política de no construir las infraestructuras relativas al agua a lo largo de las riberas del río Rímac, ha llevado a los habitantes a equiparse de sistemas artesanales rudimentarios. Las fugas ligadas a la precariedad de las conexiones ilegales de aducción de agua potable, sumadas a una canalización principal en sí obsoleta, tienden a reforzar la inestabilidad de los suelos. Justificada por la incompatibilidad de la ocupación residencial de una zona de riesgo, la negativa de rehabilitar la red por parte de las autoridades, tiende a reforzar esta dinámica. El problema es idéntico en lo que se refiere a la red de evacuación de las aguas usadas. Por falta de conexión a la red pública, esta última se hace, a menor costo, directamente al río Rímac.

La precariedad de las redes de agua y de desagüe es también un factor de inestabilidad del suelo que afecta al Cerro El Agustino. Las infiltraciones provocadas por las fugas de la red, o ligadas a las evacuaciones ilegales, han sido identificadas como una de las causas principales del hundimiento de 20 casas en el A.H. 9 de Octubre en 2003. Actualmente, esto justifica la negativa de las autoridades para rehabilitar la red de agua potable.

$\mathrm{Si}$ algunos acondicionamientos realizados por las comunidades terminan convirtiéndose en factores de riesgo, en otros casos algunas iniciativas tienden a reducirlo, ilustrando su resiliencia. Por ejemplo, siempre en el AH 9 de Octubre, los habitantes han tomado a su cargo la rehabilitación del sector tras el accidente de 2003. Han construido muros de contención, necesarios para el restablecimiento futuro de la red de agua potable, $y$ han tomado a su cargo 
la rehabilitación de la red de aguas usadas, actualmente terminada. Esta última limita las infiltraciones de agua, factor de inestabilidad de los suelos. Así, esta capacidad de organización tiende a reducir su vulnerabilidad frente al riesgo, sin por lo tanto resguardarlos de eventos de escasa probabilidad de ocurrencia pero de gran amplitud.

\section{3. 3. Los accidentes revelan el mantenimiento del proceso de construcción de la vulnerabilidad}

El caso reciente (abril de 2008) de la caída de una casa al río Rímac que causó la muerte de una persona en el $\mathrm{AH} 1^{\circ}$ de Mayo (MIRR) ilustra la acumulación de los factores de vulnerabilidad. Este accidente puede ser considerado como el resultado de las dinámicas sociales generadoras de riesgo.

La casa estaba situada al borde del talud, fuertemente expuesta a la amenaza. El asentamiento $\mathrm{AH} 1^{\circ}$ de Mayo ha sido construido sobre un antiguo botadero, y el suelo es particularmente inestable. Dos eventos agravantes vienen a sumarse a condiciones ya peligrosas. Una semana antes del accidente, dos sismos de magnitud 4,3 y 5 grados se registraron en la costa frente al Callao 16 sin causar daños. Poco tiempo antes, la rotura de una canalización de desagües había provocado la humidificación del sector. En aquel momento los habitantes se quejaron al notar fisuras en varias viviendas, e impedían el paso de vehículos pesados que hacían vibrar el suelo. El accidente se produjo una semana después.

La vivienda afectada pertenecía a una joven pareja originaria de Huánuco (departamento andino) que había llegado a Lima 4 años antes. Esta ocupaba el segundo piso de la casa y alquilaba el primer piso a una familia de migrantes. La pareja y sus tres hijos habían venido a instalarse en la MIRR en donde ya vivía un miembro de su familia. Vendedores ambulantes, su ingreso promedio era de 500 soles mensuales17.

Encontramos aquí los diferentes aspectos desarrollados anteriormente: los factores de precariedad y de pobreza que favorecen la densificación, la presencia de redes socioculturales y familiares ligadas al origen de las poblaciones migrantes, así como las ventajas que presenta la zona para las actividades de comercio ambulatorio. Aunque fue declarada inhabitable por Defensa Civil, la casa no ha sido destruida y sigue ocupada. Todos los ocupantes de la ribera fueron notificados de la obligación de abandonar la zona, por su propia seguridad. Si los accidentes reavivan la atención de las autoridades, la ausencia de cambio ilustra claramente el proceso de reforzamiento de la vulnerabilidad.

\footnotetext{
16 Los epicentros se situaron a 20 y $30 \mathrm{~km}$ respectivamente al sur del Callao (IGP-Instituto Geofísico del Perú).

17 Según el Inabif (Programa Integral Nacional para el Bienestar Familiar) 500 soles es el nivel de ingreso a partir del cual una familia puede subvenir a sus necesidades elementales: comer, beber y dormir. Por debajo de este nivel, la familia se encuentra en situación de extrema pobreza.
} 


\section{CONCLUSIÓN}

Los dos espacios de riesgo descritos en este artículo presentan un conjunto de características comunes como la marginalidad y la precariedad. Sin embargo, el análisis de los procesos de construcción de la vulnerabilidad ha permitido mostrar también algunas especificidades.

La diferencia entre estos dos espacios limeños radica a la vez en la intensidad y la frecuencia de la amenaza así como en los desafíos del desarrollo. La expropiación, medida radical, se justifica por la alta probabilidad de ocurrencia de derrumbes en la MIRR y por los desafíos de desarrollo de este espacio para la metrópoli. Por lo contrario, las laderas del Cerro El Agustino no presentan interés mayor para el desarrollo urbano, salvo el paisaje, y la probabilidad de un accidente ha sido mal evaluada allí.

El estudio ha mostrado que los factores institucionales y los modos de gobernanza de los territorios urbanos están en el corazón de la construcción de la vulnerabilidad. La inexistencia, la inefectividad o la eficacia parcial de las políticas públicas contribuyen a aumentar la exposición de la población. Así, el inmovilismo de las autoridades, asociado a la marginalidad de estos territorios, tiende a favorecer la inercia de las dinámicas sociales preexistentes, a menudo generadoras de vulnerabilidad. Sin embargo, este balance tiene que ser matizado si se contemplan las ventajas de este inmovilismo obtenidas por la población (D'Ercole \& Sierra, 2008).

Esta situación incita también a que la población tome a su cargo la resolución de los problemas. Por ende, esta busca organizarse, dotarse de equipos y tomar contacto con las ONG. Adquiere un grado de autonomía en la gestión de sus propias crisis. La organización resultante de ello puede ser considerada como un factor de resiliencia necesario por cuanto la marginalidad y la ausencia de control en periodo normal son susceptibles de verse acentuadas en caso de crisis.

En efecto, el desconocimiento de los terrenos y de la población hace difícil una gestión correcta de las necesidades y de la ayuda por parte de las autoridades públicas.

Sin embargo, los efectos positivos resultantes de una cierta forma de autonomía de la población parecen limitados. Por un lado, esta autonomía solo sería eficaz si las autoridades competentes en otras escalas aportaran los medios de urgencia necesarios, que una comunidad de algunas centenas de habitantes no puede poseer (vehículos, servicios de salud, etc.). Por otro lado, la falta de coordinación a escala metropolitana parece ser un elemento clave de los procesos de construcción de la vulnerabilidad, así como de las problemáticas de gestión de crisis.

Por último, este estudio muestra que las crisis son catalizadores de dinámicas pensadas previamente. Las acciones efectuadas tras un accidente a veces buscan directamente la reducción del riesgo ejecutando reubicaciones previstas pero difíciles de aplicar mientras otras acciones buscan simplemente restablecer el funcionamiento normal de los barrios. 


\section{Referencias citadas}

BERNAL, I. \& TAVERA, H., 2008 - Estudio de Microzonificación Sísmica en AA.HH. de Lima, 66 pp.; Lima: IGP.

COLEGIO DE INGENIEROS DEL PERÚ, 2003 - Estudio sobre vulnerabilidad del Asentamiento humano 9 de Octubre Cerro El Agustino. Informe técnico.

COOPI, 2008 - Estudio de identificación de zonas de peligro y de vulnerabilidad en el Cercado de Lima y El Agustino, Provincia de Lima, 83 pp.; Lima: Proyecto Dipecho.

D'ERCOLE, R. \& SIERRA, A., 2008 - Enjeux urbains contradictoires et vulnérabilité accrue dans un espace marginal péricentral : la rive gauche du Rímac à Lima (Pérou). Autrepart, 45: 105-122.

DEFENSA CIVIL, 2007 - Fortalecimiento Regional para la Reducción de Desastres en Ciudades Mayores de la Comunidad Andina - Síntesis, 83 pp.; Lima.

DRIANT, J.-C., 1991 - Las barriadas de Lima. Historia e interpretación, 232 pp.; Lima: IFEA, Desco.

MATOS MAR, J., 1977 - Las barriadas de Lima 1957, 294 pp.; Lima: Instituto de Estudios Peruanos. Segunda edición.

MINISTERIO DE VIVIENDA, MUNICIPALIDAD METROPOLITANA DE LIMA, s.f. - Programa de renovación urbana de la margen Izquierda y el plan de ordenamiento del eje Av. Argentina-Lima. Revista Waka, XXI: 59-67.

MUNICIPALIDAD METROPOLITANA DE LIMA, 2005 - Ordenanza n. ${ }^{\circ}$ 893-MML. http:// www.munlima.gob.pe/ordenanzas.htm

MUNICIPALIDAD METROPOLITANA DE LIMA, 2007 - Ordenanza 1020-MML. http:// www.munlima.gob.pe/ordenanzas.htm

MUNICIPALIDAD METROPOLITANA DE LIMA, 2007 - Ordenanza $n^{\circ}$ 1025-MML http:// www.munlima.gob.pe/ordenanzas.htm

PNUD, 2007 - Capitales andinas - Catálogo de instrumentos de gestión municipal en reducción de riesgos y preparativos ante emergencias de las capitales andinas, 66 pp.; Lima: Comisión Europea, PNUD, PREDECAN, MML.

RAMÍREZ CORZO D. \& RIOFRÍO, G., 2006 - Formalización de la propiedad y mejoramiento de barrios: bien legal, bien informal, 64 pp.; Lima: Desco, Programa Urbano 2006.

SIERRA, A., 2009 - Espaces à risque et marges : méthodes d'approche des vulnérabilités urbaines à Lima et Quito, 19 pp.; Cybergéo. 